FEATURE
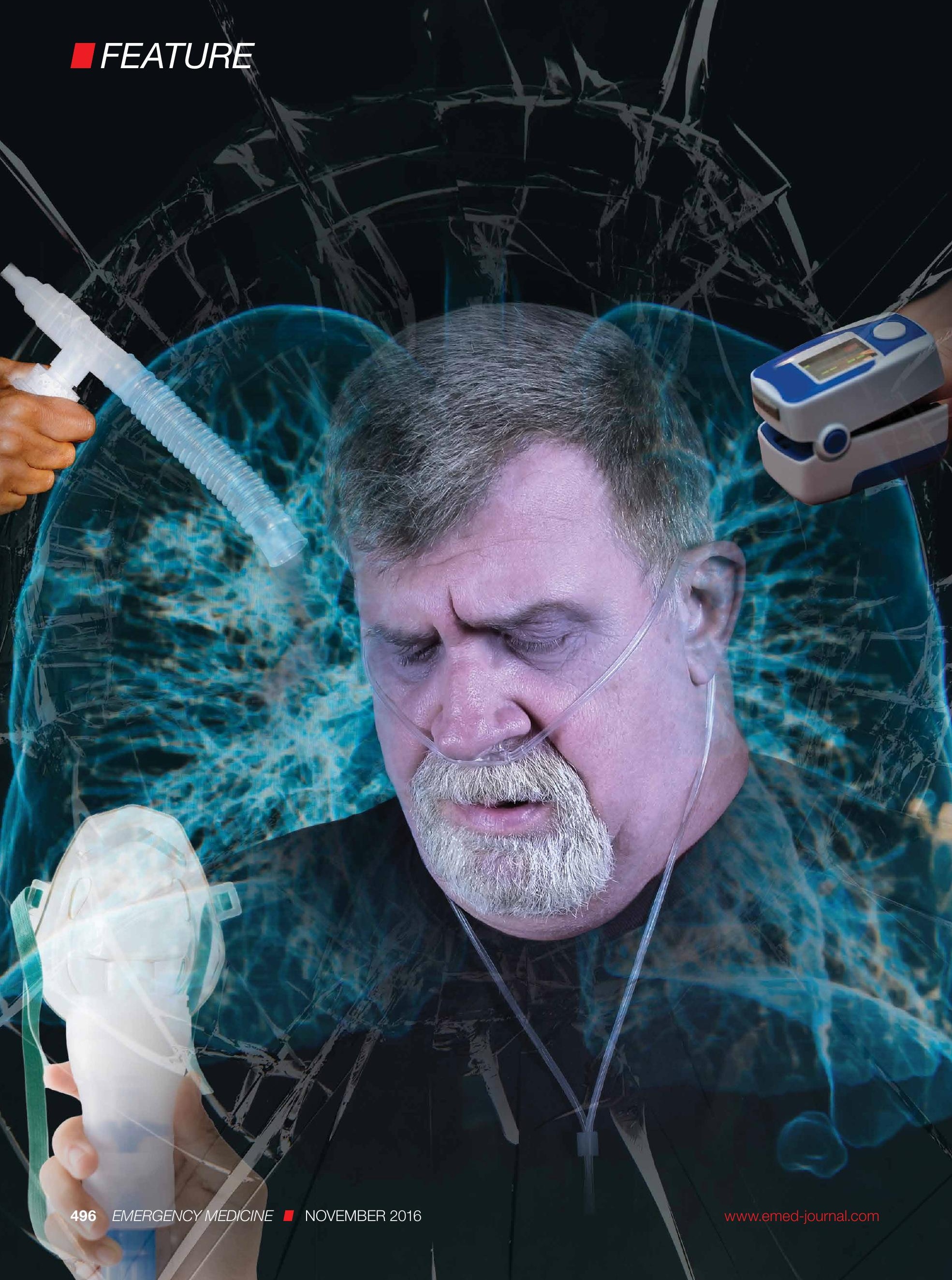


\section{The Burden of COPD}

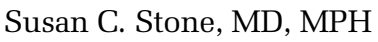

\section{Patients suffering from chronic obstructive pulmonary disease typically experience acute exacerbations and often require emergent care. However, when they begin to experience end-stage disease, many do not receive the home-based palliative care support they need.}

\section{Case Scenario}

A 62-year-old man who regularly presented to the ED for exacerbations of chronic obstructive pulmonary disease (COPD) after running out of his medications presented again for evaluation and treatment. His outpatient care had been poorly coordinated, and he relied on the ED to provide him with the support he needed. This presentation represented his fifth visit to the ED over the past 3 months.

The patient's medical history was positive for asthma since childhood, tobacco use, hypertension, and a recent diagnosis of congestive heart failure (CHF). Over the past year, he had four hospital admissions, and was currently unable to walk from his bedroom to another room without becoming short of breath. He also had recently experienced a 20-lb weight loss.

At this visit, the patient complained of chest pain and lightheadedness, which he described as suffocating. Prior to these recent symptoms, he enjoyed walking in his neighborhood and talking with friends. He was an avid reader and sports fan, but admitted that he now had trouble focusing on reading and following games on television. He lived alone, and his family lived across the country. The patient further admitted that although he had attempted to quit cigarette smoking, he was unable to give up his 50-pack per year habit. He had no completed advance health care directive and had significant challenges tending to his basic needs.

\section{The Trajectory of COPD}

Chronic obstructive pulmonary disease is a common chronic illness that causes significant morbidity and mortality. A 2016 National Health Services report cited respiratory illness, primarily from COPD, as the third leading cause of death in the United States in 2014. ${ }^{1}$ The trajectory of this disease is marked by frequent exacerbations with partial recovery to baseline function. The burden of those living with COPD is significant and marked by a poor overall health-related quality of life (QOL). The ED has become a staging area for patients seeking care for exacerbations of COPD. ${ }^{2}$

The World Health Organization (WHO) and the Global Initiative for Chronic Ob-

Dr Stone is the director of supportive and palliative care medicine, St Joseph's Health, Santa Rosa, California.

Author's Disclosure Statement: The author reports no actual or potential conflict of interest in relation to this article.

DOI: 10.12788/emed.2016.0066 
structive Lung Disease (GOLD) have defined COPD as a spectrum of diseases including emphysema, chronic bronchitis, and chronic obstructive asthma characterized by persistent airflow limitation that is usually progressive and associated with an enhanced chronic inflammatory response to noxious particles or gases in the airways and lungs. ${ }^{3}$ Exacerbations and comorbidities contribute to the overall severity of COPD in individual patients. ${ }^{4}$

The case presented in this article illustrates the common scenario of a patient whose COPD has become severe and highly symptomatic with declining function to the point where he requires home support. His physical decline had been rapid and resulted in many unmet needs. When a patient such as this presents for emergent care, he must first be stabilized; then a care plan will need to be developed prior to discharge.

\section{Management Goals}

The overall goals of treating COPD are based on preserving function and are not curative in nature. Chronic obstructive pulmonary disease is a progressive illness that will intensify over time. ${ }^{5}$ As such, palliative care services are warranted. However, many patients with COPD do not receive palliative care services compared to patients with such other serious and life-limiting disease as cancer and heart disease.

\section{Acute Exacerbations of COPD Incidence}

The frequency of acute exacerbations of COPD (AECOPD) increases with age, productive cough, long-standing COPD, previous hospitalizations related to COPD, eosinophilia, and comorbidities (eg, CHF). Patients with moderate to severe COPD and a history of prior exacerbations were found to have a higher likelihood of future exacerbations. From a quality and cost perspective, it may be useful to identify high-risk patients and strengthen their out- patient program to lessen the need for ED care and more intensive support. ${ }^{6,7}$

In our case scenario, the patient could have been stabilized at home with a wellcontrolled plan and home support, which would have resulted in an improved QOL and more time free from his high symptom burden.

\section{Causes}

Bacterial and viral respiratory infections are the most likely cause of AECOPD. Environmental pollution and pulmonary embolism are also triggers. Typically, patients with AECOPD present to the ED up to several times a year ${ }^{2}$ and represent the third most common cause of 30-day readmissions to the hospital. ${ }^{8}$ Prior exacerbations, dyspnea, and other medical comorbidities are also risk factors for more frequent hospital visits.

\section{Presenting Signs and Symptoms}

Each occurrence of AECOPD represents a worsening of a patient's respiratory symptoms beyond normal variations. This might include increases in cough, sputum production, and dyspnea. The goal in caring for a person with an AECOPD is to stabilize the acute event and provide a treatment plan. The range of acuity for moderate to severe disease makes devising an appropriate treatment plan challenging, and after implementing the best plans, the patient's course may be characterized by a prolonged cycle of admissions and readmissions without substantial return to baseline.

\section{Management}

In practice, ED management of AECOPD in older adults typically differs significantly from published guideline recommendations, ${ }^{9}$ which may result in poor outcomes related to shortcomings in quality of care. Better adherence to guideline recommendations when caring for elderly patients with COPD may lead to improved clinical outcomes and better resource usage. ${ }^{6,9}$ 


\section{Antibiotic Therapy}

Antibiotics are indicated for patients with moderate to severe AECOPD who are ill enough to be admitted to the hospital. Empiric broad spectrum treatment is recommended. The initial antibiotic regimen should target likely bacterial pathogens (Haemophilus influenzae, Moraxella catarrhalis, and Streptococcus pneumoniae in most patients) and take into account local patterns of antibiotic resistance. Flouroquinolones or third-generation cephalosporins generally provide sufficient coverage. For patients experiencing only a mild exacerbation, antibiotics are not warranted.

\section{Magnesium Sulfate}

Other supplemental medications that have been evaluated include magnesium sulfate for bronchial smooth muscle relaxation. Studies have found that while magnesium is helpful in asthma, results are mixed with COPD. ${ }^{16}$

\section{Supplemental Oxygen}

Oxygen therapy is important during an AECOPD episode. Often, concerns arise about decreasing respiratory drive, which is typically driven by hypoxia in patients who have chronic hypercapnia. Arterial blood gas determinations are important in managing a patient's respiratory status and will assist in determining actual oxygenation and any coexistent metabolic disturbances.

Noninvasive Ventilation. Oxygen can be administered efficiently by a venturi mask, which delivers precise fractions of oxygen, or by nasal cannula. A facemask is less comfortable, but is available for higher oxygen requirements, providing up to $55 \%$ oxygen, while a nonrebreather mask delivers up to $90 \%$ oxygen.

When necessary, noninvasive positive pressure ventilation (NPPV) improves outcomes for those with severe dyspnea and signs of respiratory fatigue manifested as increased work of breathing. Noninvasive positive pressure ventilation can improve clinical outcomes and is the ventilator mode of choice for those patients with COPD. Indications include severe dyspnea with signs of increased work of breathing and respiratory acidosis (arterial $\mathrm{pH}<7.35$ ) and partial pressure of arterial carbon dioxide $\left(\mathrm{PaCO}_{2}\right)>45 \mathrm{~mm} \mathrm{Hg}$.

Whenever possible, NPPV should be initiated with a triggered mode to allow spontaneous breaths. Inspiratory pressure of 8 cm to $12 \mathrm{~cm} \mathrm{H}_{2} \mathrm{O}$ and expiratory pressure of $3 \mathrm{~cm}$ to $5 \mathrm{~cm}$ of $\mathrm{H}_{2}$ are recommended.

Mechanical Ventilation. Mechanical ventilation is often undesirable because it may be extraordinarily difficult to wean a patient off the device and permit safe extubation. However, if a patient cannot be stabilized with NPPV, intubation and mechanical ventilation must be considered. Typically, this occurs when there is severe respiratory distress, tachypnea $>30$ breaths/min, accessory muscle use, and altered mentation.

Goals of intubation/mechanical respiration include correcting oxygenation and severe respiratory acidosis as well as reducing the work of breathing. Barotrauma is a significant risk when patients with COPD require mechanical ventilation. Volume-limited modes of ventilation are commonly used, while pressure support or pressure-limited modes are less suitable for patients with airflow limitation. Again, invasive ventilation should only be administered if a patient cannot tolerate NPPV.

\section{Palliative Care in the ED}

Palliative care is an approach that improves the QOL of patients and their families facing the issues associated with life-threatening illness, through the prevention and relief of suffering by means of early identification and accurate assessment and treatment of pain and physical, psychosocial, and spiritual problems. ${ }^{3}$ This approach to care is warranted for COPD patients given the myriad of burdensome symptoms and functional decline that occurs. ${ }^{17}$ 
Palliative care expands traditional treatment goals to include enhancing QOL; helping with medical decision making; and identifying the goals of care. Palliative care is provided by board-certified physicians for the most complex of cases. However, the primary practice of palliative care must be delivered at the bedside by the treating provider. Managing pain, dyspnea, nausea, vomiting, and changes in bowel habits, as well as discussing goals of care, are among the basic palliative care skills all providers need to have and apply when indicated.

\section{Palliative Care for Dyspnea}

Opioids. Primary palliative care in the ED includes the appropriate use of low-dose oral and parenteral opioids to treat dyspnea in AECOPD. The use of a low-dose opioid, such as morphine $2 \mathrm{mg}$ IV, titrated up to a desired response, is a safe and effective practice. ${ }^{18}$ Note the 2 -mg starting dose is considered low-dose. ${ }^{19}$

With respect to managing dyspnea in AECOPD patients, nebulized opioids have not been found to be better than nebulized saline. More specific data regarding the use of oral opioids for managing refractory dyspnea in patients with predominantly COPD have been recently published: Long-acting morphine $20 \mathrm{mg}$ once daily provides symptomatic relief in refractory dyspnea in the community setting. For the opioid-naïve patient, a lower dose is recommended..$^{20}$

Oxygenation. There is no hard evidence of the effectiveness of oxygen in the palliation of breathlessness. Humidified air is effective initially, as is providing a fan at the bedside. Short-burst oxygen therapy should only be considered for episodes of severe breathlessness in patients whose COPD is not relieved by other treatments. Oxygen should continue to be prescribed only if an improvement in breathlessness following therapy has been documented. The American Thoracic Society recommends continuous oxygen therapy in pa- tients with COPD who have severe resting hypoxemia $\left(\mathrm{PaCO}_{2} \leq 55 \mathrm{~mm} \mathrm{Hg}\right.$ or $\mathrm{SpO}_{2}$ $\leq 88 \%){ }^{21}$

\section{POLST Form}

The Physicians Order for Life-Sustaining Treatment (POLST) form is a set of medical orders, similar to the "do not resuscitate" (allow natural death) order. A POLST form is not an advance directive and does not serve as a substitute for a patient's assignation of a health care agent or durable power of attorney for health care..$^{22}$

The POLST form enables physicians to order treatments patients would want, identify those treatments that patients would not want, and not provide those the patient considers "extraordinary" and excessively burdensome. A POLST form does not allow for active euthanasia or physician-assisted suicide.

Identifying treatment preferences is an important part of the initial evaluation of all patients. When dealing with an airway issue in a COPD patient, management can become complex. Ideally, the POLST form should arrive with the patient in the $\mathrm{ED}$ and list preferences regarding possible intensive interventions such as intubation and chest compressions. Discussing these issues with a patient in extreme distress is difficult or impossible, and in these cases, access to pertinent medical records, discussing preferences with family caregivers, and availability of a POLST form are much better ways to determine therapy.

\section{Palliative Home Care}

\section{Patient Safety Considerations}

Weight loss and associated muscle wasting are common features in patients with severe COPD, creating a high-risk situation for falls and a need for assistance with activities of daily living. The patient who is frail when discharged home from the ED requires a home-care plan before leaving the ED, and strict follow-up with the patient's primary care provider will typically be needed within 2 to 4 weeks. 


\section{Psychological Considerations}

Being mindful of the anxiety and depression that accompany the physical limitations of those with COPD is important. Mood disturbances serve as risk factors for re-hospitalization and mortality. ${ }^{13}$ Multiple palliative care interventions provide patients assistance with these issues, including the use of antidepressants that may aid sleep, stabilize mood, and stimulate appetite.

Early referral to the palliative care team will provide improved care for the patient and family. Palliative care referral will provide continued management of the physical symptoms and evaluation and treatment of the psychosocial issues that accompany COPD. Additionally, the palliative care team can assist with safe discharge planning and follow-up, including the provision of the patient's home needs as well as the family's ability to cope with the home setting.

\section{Prognosis}

Predicting prognosis is difficult for the COPD patient due to the highly variable illness trajectory. Some patients have a low $\mathrm{FEV}_{1}$ and yet are very functional. However, assessment of severity of lung function impairment, frequency of exacerbations, and need for long-term oxygen therapy helps identify those patients who are entering the final 12 months of life. Evaluating symptom burden and impact on activities of daily living for patients with COPD is comparable to those of cancer patients, and in both cases, palliative care approaches are necessary.

\section{Predicting Morbidity and Mortality}

A profile developed from observational studies can help predict 6- to 12-month morbidity and mortality in patients with advanced COPD. This profile includes the following criteria:

- Significant dyspnea;

- $\mathrm{FEV}_{1}<30 \%$;

- Number of exacerbations;

- Left heart failure or other comorbidities;

- Weight loss or cachexia;
- Decreasing performance status;

- Age older than 70 years; and

- Depression.

Although additional research is required to refine and verify this profile, reviewing these data points can prompt providers to initiate discussions with patients about treatment preferences and end-of-life care. $^{23,24}$

\section{Palliative Performance Scale}

The Palliative Performance Scale (PPS) is another scale used to predict prognosis and eligibility for hospice care. ${ }^{25}$ This score provides a patient's estimated survival. ${ }^{25}$ For a patient with a PPS score of $50 \%$, hospice education may be appropriate.

\section{Case Scenario Continued}

Both the BODE and GOLD criteria scores assisted in determining prognosis and risk profiles of the patient in our case scenario. By applying the BODE criteria, our patient had a 4-year survival benefit of under $18 \%$. The GOLD criteria results for this patient also were consistent with the BODE criteria and reflected end-stage COPD. Since this patient also had a PPS score of $50 \%$, hospice education and care were discussed and initiated.

\section{Conclusion}

Patients with AECOPD commonly present to the ED. Such patients suffer with a high burden of illness and a need for immediate symptom management. However, after these measures have been instituted, strong evidence suggests that these patients typically do not receive palliative care with the same frequency compared to cancer or heart disease patients.

Management of AECOPD in the ED must include rapid treatment of dyspnea and pain, but also a determination of treatment preferences and an understanding of the prognosis. Several criteria are available to guide prognostic awareness and may help further the goals of care and disposition. Primary palliative care should be started by the
Being mindful

of the

anxiety and

depression that

accompany

the physical

limitations of

those with

COPD is

important. 
ED provider for appropriate patients, with early referral to the palliative care team.

\section{References}

1. National Center for Health Statistics. Health, United States 2015 With Special Feature on Racial and Ethnic Health Disparities. Hyattsville, MD: US Dept. Health and Human Services; 2016. http://www.cdc. gov/nchs/hus/. Accessed October 17, 2016.

2. Khialani B, Sivakumaran P, Keijzers G, Sriram KB. Emergency department management of acute exacerbations of chronic obstructive pulmonary disease and factors associated with hospitalization. J Res Med Sci. 2014;19(4):297-303.

3. World Health Organization Web site. Chronic respiratory diseases. COPD: Definition. http://www. who.int/respiratory/copd/definition/en/. Accessed October 17, 2016.

4. Rabe KF, Hurd S, Anzueto A, et al; Global Initiative for Chronic Obstructive Lung Disease. Global strategy for the diagnosis, management, and prevention of chronic obstructive pulmonary disease: GOLD executive summary. Am J Respir Crit Care Med. 2007;176(6):532-555.

5. Fan VS, Ramsey SD, Make BJ, Martinez FJ. Physiologic variables and functional status independently predict COPD hospitalizations and emergency department visits in patients with severe COPD. COPD. 2007;4(1):29-39.

6. Cydulka RK, Rowe BH, Clark S, Emerman CL, Camargo CA Jr; MARC Investigators. Emergency department management of acute exacerbations of chronic obstructive pulmonary disease in the elderly: the Multicenter Airway Research Collaboration. J Am Geriatr Soc. 2003;51(7):908-916.

7. Strassels SA, Smith DH, Sullivan SD, et al. The costs of treating COPD in the United States. Chest. 2001;119:3.

8. Jencks SF, Williams MV, Coleman EA. Rehospitalizations among patients in the Medicare fee-for-service program. N Engl J Med. 2009;360(14):1418-1428. doi:10.1056/NEJMsa0803563.

9. Rowe BH, Bhutani M, Stickland MK, Cydulka R. Assessment and management of chronic obstructive pulmonary disease in the emergency department and beyond. Expert Rev Respir Med. 2011;5(4):549-559. doi:10.1586/ers.11.43.

10. National Institute for Clinical Excellence Web site. Chronic obstructive pulmonary disease in over 16s: diagnosis and management. Clinical Guideline CG101. https://www.nice.org.uk/Guidance/cg101. Published June 2010. Accessed October 17, 2016.

11. Christensen VL, Holm AM, Cooper B, Paul SM, Miaskowski C, Rustøen T. Differences in symptom burden among patients with moderate, severe, or very severe chronic obstructive pulmonary disease. J Pain Symptom Manage. 2016;51(5):849-859. doi:10.1016/j.jpainsymman.2015.12.324

12. GOLD Reports. Global Initiative for Chronic Obstruc- tive Lung Disease Web site. http://goldcopd.org/ gold-reports/. Accessed October 17, 2016.

13. Funk GC, Kirchheiner K, Burghuber OC, Hartl S. BODE index versus GOLD classification for explaining anxious and depressive symptoms in patients with COPD-a cross-sectional study. Respir Res. 2009;10:1. doi:10.1186/1465-9921-10-1.

14. Bach PB, Brown C, Gelfand SE, McCrory DC; American College of Physicians-American Society of Internal Medicine; American College of Chest Physicians. Management of acute exacerbations of chronic obstructive pulmonary disease: a summary and appraisal of published evidence. Ann Intern Med. 2001;134(7):600-620.

15. McCrory DC, Brown CD. Inhaled short-acting beta 2-agonists versus ipratropium for acute exacerbations of chronic obstructive pulmonary disease. Cochrane Database Syst Rev. 2001;(2):CD002984.

16. Shivanthan MC, Rajapakse S. Magnesium for acute exacerbation of chronic obstructive pulmonary disease: A systematic review of randomised trials. Ann Thorac Med. 2014;9(2):77-80. doi:10.4103/18171737.128844.

17. Curtis JR. Palliative and end of life care for patients with severe COPD. Eur Respir J. 2008;32(3):796-803.

18. Rocker GM, Simpson AC, Young J, et al. Opioid therapy for refractory dyspnea in patients with advanced chronic obstructive pulmonary disease: patients' experiences and outcomes. CMAJ Open. 2013;1(1):E27-E36.

19. Jennings AL, Davies AN, Higgins JP, Gibbs JS, Broadley KE. A systematic review of the use of opioids in the management of dyspnea. Thorax. 2002;57(11):939-944

20. Abernethy AP, Currow DC, Frith P, Fazekas BS, McHugh A, Bui C. Randomised, double blind, placebo controlled crossover trial of sustained release morphine for the management of refractory dyspnoea. BMJ. 2003;327(7414):523-528.

21. Qaseem A, Wilt TJ, Weinberger SE, et al; American College of Physicians; American College of Chest Physicians; American Thoracic Society; European Respiratory Society. Diagnosis and management of stable chronic obstructive pulmonary disease: a clinical practice guideline update from the American College of Physicians, American College of Chest Physicians, American Thoracic Society, and European Respiratory Society. Ann Intern Med. 2011;155(3):179-191. doi:10.7326/0003-4819-155-3201108020-00008.

22. National POLST Paradigm. http://polst.org/professionals-page/?pro=1. Accessed October 17, 2016.

23. Hansen-Flaschen J. Chronic obstructive pulmonary disease: the last year of life. Respir Care. 2004;49(1):90-97; discussion 97-98.

24. Spathis A, Booth S. End of life care in chronic obstructive pulmonary disease: in search of a good death. Int J Chron Obstruct Pulmon Dis. 2008;3(1):11-29.

25. Anderson F, Downing GM, Hill J, Casorso L, Lerch N. Palliative performance scale (PPS): a new tool J Palliat Care. 1996;12(1):5-11. 